\title{
Bridging the Disconnect Between Academic Institutions and Employers in the 4th Industrial Revolution
}

\author{
Nicole Rakowski \\ McMaster University
}

\begin{abstract}
The skills gap is widening and causing greater inequality in the today's workplace. Bridging the disconnect between academic institutions and employers in the 4th industrial revolution is of critical importance to the success of our current market.

Combining and analyzing both qualitative data gathered from key focus groups and a literature review, it is evident that a commitment to self- directed learning requires students and faculty to both understand the value of empowering learning, and to take increased responsibility for decision making. Academic institutions need to address skills required to become self-directed learners and must present students with the environment that lets them be more self-directed. Employers on the other hand must provide institutions with the skills they require upon hiring.
\end{abstract}

\section{Acknowledgement}

Funding for this project was provided by the MacPherson Institute of McMaster University as part of the Student Partners Program.

This project was also initiated and completed in partnership with Career Development and Cooperative Education, Faculty of Science, McMaster University.

The skills gap is widening and causing greater inequality in today's workplace (Alison, 2021). Our economy within the fourth industrial revolution is skewed towards the highly talented, yielding a greater inequality - particularly within the labour market (World Economic Forum, 2021). The fourth industrial revolution, a term coined by the founder of the World Economic Forum - Klaus Schwab - is the reality of connected technology whereby individuals are able to manage their lives digitally (Xu et al. 2018). As a result, there are social consequences for those graduating from academic institutions during this technological revolution and the gap between efficiency and market value continues to widen (Muhleisen, 2018). Automation will continue to substitute labour across the global economy, and the displacement of employed individuals by machines may exacerbate the gap between returns to labour and capital (Xu et al. 2018). The most valuable and scarcest resource at this time is neither traditional labour or capital, but rather innovators. The acquisition of talent will give rise to a labour market that is segregated. Those that are relatively lower skilled and have lower wages will be repossessed by digitization, while those with advanced skills and higher wages will remain untouched. This disjunction is what will lead to social consequences (Xu et al. 2018). Newer technologies have taken power over traditional means of operating. Netflix is competing with cable TV; taxis are competing with Uber and Lyft (Xu et al. 2018), and the list goes on.

The way in which we live has been dramatically altered not to mention the effects of the COVID-19 pandemic. While neither the outcome of the pandemic nor the technological revolution was ever initially predicted, one thing is for certain - the response to the transformation must involve an integrated and comprehensive process whereby the global polity is included in the decision making power. Why? This revolution is unlike any of the ones that preceded. The speed, scale and complexity is unmatched and has the potential to lead to extreme inequality that can significantly transform the world we live in (Xu et al. 2018). Students feel lost, and there is a miscommunication between ex- 
pectations and desired outcomes. Many have no idea how to make themselves stand out from the rest of the population, making it extremely difficult to transition from academia to employment. Understanding the current institutional barriers along with what employers are seeking must be included in the solvable equation.

\section{The Initial Realization}

It wasn't until I was sitting in my graduation ceremony, hearing the names of hundreds of students being called across the stage that I realized we all learned the exact same thing, had the exact same grades, produced the exact same work and were given the same essay topics. I watched as each of us walked across that stage like objects on a production line smiling not having a clue what we would do next. There was no standing out. I looked at my fellow students and really thought to myself that we are all the same. Surely one student may have gotten 5 percent higher than another on a test, and they may have run faster than the previous in sports, but they were all pretty much the same. Leaving that graduation ceremony felt as much of a success as it did as an inconclusive essay, where the subjects were identifiable, but the plot remained unfinished.

But academic institutions are not solely to blame for this lack of confidence instilled in their student population. As I left that graduation ceremony, I realized that nowhere along my education- al trajectory had employers been connected to my program. I was left with raw knowledge and skills that I questioned were applicable to the real world. Of course this is not every students' experience, but this was mine.

\section{Research}

After years of trying to find my path transitioning from academia to experiential learning, I began to realize the existing challenges that needed further exploration - the lack of clarity around defining self-directed learning, the expectations and skills that employers sought out and the question around whether I was taking the appropriate academic path that would one day lead me to my future interview. Speaking with other fellow peers, they too felt they were left with raw knowledge that they were not sure how to translate. I decided to explore what other like-minded institutions were already researching and wanted to build upon their foundational knowledge.

I became the lead researcher of the Students Partner Project, specifically, Preparing Science Graduate Students for Career Success, at McMaster University and began my analysis by conducting an in-depth literature reviews. Topics included: Self-guided education theory, self-directed learning (SDL), strategies for engaging students in career content, evidence-based research on why this topic is important, and what a hybrid approach to engaging students and supporting them in skills development may look like. In addition to the literature review, I conducted key informant focus groups with students who used the services of the Science Career \& Cooperative Education department. This department offers cooperative education, career education, and experiential education for Faculty of Science Students at McMaster University.

\section{Understanding Institutional Barriers}

After conducting the preliminary literature review and theming analysis using an inductive approach, one of the greatest issues identified is the lack of consistency in defining self-directed learning. The second greatest issue is that there is no conceptual framework that is standardized amongst academic institutions. The thematic analysis stemmed from initial coding. Codes were identified by highlighting certain sections of the data, and then coming up with shortened labels to describe the information. Themes were then generated based on patterns identified and grouping of codes. The inconsistent use and descriptions to define SDL leads to communication difficulties when examining the concept and creates immense confusion as to how universities should facilitate its outset.

Based on the focus groups conducted with students, the findings suggested that students are left feeling controlled by institutional settings and their motivation for self-pursuing their 
own passion declines. One student stated, "I often feel trapped because I am given topics to research as opposed to choosing what I am really passionate about. Therefore, I have no motivation to complete my work and my grades fall flat. I am left researching something that I have no interest about and am penalized for my effort."

According to Bain (2021), our desire to do something decreases if we have the feeling someone is controlling us. Extrinsic motivators that may be seen as means of control, such as grades, suppress one's internal desires to learn innately, and force students to learn by conditioning. Traditionally, academic institutions have been primed to create a culture that consists of memorizing information (Bain, 2021). This learning structure forces students to memorize correct multiple choice questions rather than encouraging them to be interested in the content themselves. Authors such as Bain (2021) and Caldwell (2020) argue that the concentration is on telling students what they need to remember without having them understand how to apply, synthesize and evaluate the content. As a result, students are unable to translate knowledge learned to real life experiences and instinctive curiosity is inhibited. For example, you can tell someone how to serve a volleyball, but will not be able to fully understand the experiential component without actually practicing it. If students are not completing courses with a burning desire to learn more, the academic system has failed its learners.
In terms of academic teaching style in certain parts of the world, traditionally, professors and instructors are taught to dictate learning rather than cultivating an environment where intrigue is brought to the forefront (Bain, 2021). This traditional learning structure where education relies on fear and power to stimulate interest in learning (for instance, telling a student "this will be on the test" or "your grades depend on this") only strengthens the disconnect between academia and employers. Environments inevitably shape behaviour related to cognition (Dweck \& Murphy, 2009). Institutions rank students against each other and consciously embody the 'genius theory of learning' (Bain, 2021), surreptitiously implying that you are either smart or not. Students then feel less motivated to compete amongst those 'toptiered' learners as their grades are displayed next to each other, subliminally promoting working alone rather than collaboratively (Bain, 2021). A study by Trzesniewski et al (2006). at the University of Michigan discovered that $80 \%$ of students surveyed based their selfworth on academic performance. We are told to stay in school in order to get good grades if we want to succeed in life. The catch is students fear negative outcomes, which impedes their learning. A study conducted by Rogerseon \& Scott (2010) found that the fear of potentially failing led to "classic symptoms of procrastination and avoidance" along with low self-esteem. Another found that students were far less likely to take on challenging tasks when grades were involved (Harter, 1978), but far more likely to seek out challenging problems without a grading system (Deci et al. 1996). It is important to caution against institutions being taught to concentrate on correcting students' work rather than providing feedback while letting the student take charge of their own pursuits. The "correction" approach leads to increased dropout rates and significantly decreases morale (Bain, 2021).

\section{Impact of the Fourth Industrial Revolution}

Academic institutions are not solely to blame for the situation mentioned previously. Companies today have a lot more market competition (Gandolf, 2021) while dealing with reduced profit margins, and at the same time they are dealing with an exponential speed of modern breakthroughs that has no historical precedent (Xu et al. 2018). We are no longer evolving at a linear pace, heralding the transformation of governance structures and systems of production. Global shareholders have this weaponized financial capital that never existed years ago where companies cannot underperform - one example being the Saudi Sovern Wealth Fund (Young, 2020). This wealth fund, also known as the Public Investment Fund (Salzman, 2020), has aggressively invested its $\$ 360$ billion around the world into developing and underdeveloped sectors. In turn, compression on their margins becomes an existentially financial 
threat for companies and they are forced to reduce the expenditures on employee development.

One strategy for overcoming this systemic issue is continuing to increase the public financial market where financial commodities are traded for immediate delivery of talent (Kumar \& Tan, 2018; $\mathrm{Hu} \& \mathrm{Ma}$, 2016; Kwarteng, 2014), through means such as online licensing programs. This online instrument could include an experiential component that can be used for individuals globally, regardless of location. It is apparent that skills in today's economy require a self-directed learning approach, with experiential learning being part of that learning. Technology is one means for connecting students to the right employers - it is a means that has the capability to connect billions of people through mobile devices (Reed et al. 2014). Connection through unprecedented processing power, storage capabilities and access to knowledge is incalculable.

In our global market, we have a supply side and demand side dislocation (Garnero \& Pagani, 2021). In other words, in our supply side of the labour market, we are seeing the rise of retirement stemming from the baby boomer population while at the same time have increasingly competitive markets for global talent (Douglass \& Edelstein, 2009). Although the COVID pandemic has diminished labour market participation, corporations have been outsourcing talent globally to meet the needs of companies (Pissarides, 2020; Erickson \& Norlander,
2021). On the demand side, we are in the fourth industrial revolution where the type of talent companies are looking for is changing. Many jobs are automated and we have a rise of remote work and project succession (Leonard, 2020). It is apparent that companies are trying to figure out their hiring profile as they can hire globally as opposed to limiting the application pool to their inner city population.

\section{Potential Solution}

In my opinion, we do not need more courses. What we do need is a global online platform that has wrap around services that can support students matching their skills set with the appropriate employers. Based on my experience as a student, sessional faculty at McMaster University and researcher, employers can be the ones that provide these supportive skills and help them understand the threats they may face within the new revolution we are in. Constant self-development is crucial for keeping up with the global change of pace and the majority of people do not understand that the change of pace is accelerating far beyond the norm. We are seeing rapid advancements and breakthroughs in fields such as robotics, nanotechnology, quantum computing and many others (World Economic Forum, 2016). The problem is that it is difficult to train individuals for general white-collar work without knowing exactly what they are going to do with their desired path. In terms of a global solution, there needs to be a culture shift that draws the model of education from preparing students for something extremely specific to train them universally to have transferable skills (Lazenbnikova et al. 2019; Nagele \& Stalder, 2017). Transferable skills in relation to employability are significantly important and competition nowadays requires students to offer an employer more than just academic achievements (Muhamad, 2012). In my own experience, the skills I have acquired throughout my lifetime are my most valuable assets that employers have noticed. If I knew which skills employers required up front however, I could have significantly enhanced my profile and perhaps been even more prepared. Employers and corporations need to provide institutions with the soft skills they require, early on in a student's trajectory so that they have the time to develop these skills and apply them in practice. As we all try to navigate this changing economy, it is important that we think about our existing skills and how we can apply these to our daily lives. Taking a moment to identify these crucial skills may help to determine the skills that one is potentially lacking or missing.

\section{Applying our Innate Creativity to Shaping Future Models}

Studies have shown that if you let children follow their own curiosity, "they will learn by tinkering about, discovering something new, and teaching each other" (Bain, 2021; Jirout, 2020; 
Berlyne, 1954; Howard-Jones \& Demetrious, 2009). The thirst for knowledge is intrinsic in our ancient DNA and each of us is born with insatiable curiosity (Bain, 2021). How can institutions put a grade on someone's thinking? Inextricably, how can employers demand certain hard skills when wanting to increase their innovative side while employing critical problem-solving skills? In other words, how do we prevent stagnancy? Discontent amongst our population is fueled by the pervasiveness of rigid viewpoints and propagated by unrealistic expectations. How can the corporate sector decide what constitutes as success for an individual or a group when creativity is subjective?

Based on my thematic analysis from the focus groups and my own experience navigating through the system, I argue that most importantly, institutions need to better prepare students for the employability in the real world. Second, employers need to be more heavily involved in a students' academic trajectory. Third, societies reliance on rigid testing and grading structures prevents the exploration or curiosity, thus hindering our ability to problem solve. The only way our society can advance is by teaching transferable skills throughout the entirety of one's academic journey, increasing employer involvement at the institution level and by not conforming to standard answers and developing something new. Sure, some may debate that there are merits of rigid testing that is based on logic and evidence, but wouldn't this curb our curiosity to some extent? How can we, as human beings, think that we can tell someone the exact quality of their thinking ability with scientific accuracy that might otherwise used to measure velocity or some complex physics equation? The truth is we can't.

\section{Although I am a strong} enthusiast when it comes to the adoption of new technologies within the Fourth Industrial Revolution, I do question whether the inexorable integration of modern methodologies inhibits quintessential human capacities such as creativity.

\section{Strategies for Addressing the Disconnect between Academia and Employers}

Having control over one's own learning situation is only one component of self-directed learning. According to Bain (2021) and other authors such as du Toit-Brits (1975), self-directed learning is also based on one's willingness to learn, how they choose to apply their critical judgement skills and knowing what options are available. With this said, institutions must take into account and adapt to the learning situations to varying stages of self-directed students (Bain 2021). In order to create strong learning environments, academic institutions must be conscious of the vast differences that exist in regards to the ability of and will of students to self-direct themselves. When looking at system transformational strategies, institutions need to help students understand that they are the authors of their own work and help them learn to self-assess their surrounding environment.

Addressing the disconnect between current education programs and the skills employers require is of critical importance. Based on the literature highlighted above and from my own experiences, there are two skills that are often overlooked in terms of their importance but are absolutely vital to success. The first skill is communication-in both written and verbal form. The second, is teamwork skills- espeically given our diverse and rapidly evolving global systems that we are interconnected within. Teamwork and interpersonal skills connect us to the critical thinking we need to inform change.

One of the first steps in solving existing barriers is understanding the problem we have at hand. Without fully understanding the issues, an effective framework cannot be built. Based on the focus groups with students at McMaster University, it is apparent that students have skills but they are not able to translate those skills, and second, students are going through school then stopping. However, learning is not a onetime interaction, but rather a lifelong journey. The skills employers seek do not match with the skills current job seekers possess (Nijhof \& Brandsma, 1999; Mishra \& Mishra, 2019). Some are seeking hard skills which really only have a short half-life because they are continuously evolving, whereas 
soft skills are the ones that carry students throughout life's journey (Appleby, 2017).

As mentioned, students can memorize information, but if they are unable to transfer that knowledge it is essentially useless. We need to change the paradigm to incorporate experiential leaning and ask ourselves, how can the academic journey be an experience rather than just another requirement that must be completed?

\section{Conclusion}

Some countries may be more open to sharing ideas than other countries, and some may be better at attracting and retaining talent in a race to outperform their competitors. Some may way to protect their resources rather than share them globally on the talent podium. However, global companies must also realize that failure to acknowledge global shifts in accordance with the technological revolution will result in hampering a company's uptake on new technologies and will leave them trailing behind more agile competitors.

Globally, we are accelerating towards obtaining micro-credentials, which are essentially rapid training programs offered by academic institutions. Employers on the other hand need to be ready on the other side of the equation to provide students with reimbursement for obtaining those credentials. The global labour deficit is expected to reach nearly $\$ 8.5$ trillion by 2030 , and this is said to be attributed to the widening gap between higher education and industry (Matern, 2020). Although many are providing those options, they do not have official partnerships with the educational system (Lambert, 2021). A study by the Strada Education Network and Gallup (2018) found that 57\% of hiring managers are not confident in their company's ability to employ the right talent from institutions (Lambert, 2021). This means employers must spend more in their development programs and there is a disconnect between what academia is teaching and the actual needs of the market (Lambert, 2021). Thus, designing a new framework would help to address the connectivity issues and boost partnership agreements. In supporting the notion of micro-credentials, from my own experience and that of the focus groups', some employers and institutions are heavily focused on transcripts. Grades however do not show your skills. We have faculty members that are constantly working on planning these great courses, but these courses do not explain what skills you have just acquired and thus students have no idea what skills they may just have obtained in a course. One student stated, "after completing an English literature course, I knew the difference between several authors but that was about it. I don't really know if I gained a skill or improved an existing one." Designing a system that maps your skills, rather than just grades would help students by providing them with a tool to know what skills they just acquired no matter where they are in their education process. This type of transcript could potentially be a students' greatest return of investment upon graduation.

Furthermore, alumni that have been successfully integrated into the work force need to be brought back to academic institutions. They are the ones that can work with individuals in the community that are stunted because of their lack of skills and can guide them on a path that allows them to find the right program with supports in place.

Combining and analyzing both the qualitative data gathered from the participants and the information obtained from the literature, commitment to self- directed learning requires both students and faculty to understand the value of empowering learning to take increased responsibility for decision making. Academic institutions need to address skills required to become self-directed learners and must present students with the environment that lets them be more self-directed.

\section{Recommendations}

As stated by Nordstrom \& Ridderstrale (2001), our global economies of scale are creating "surplus societies that have a surplus of similar companies, employing similar people with similar educational backgrounds, having them come up with similar ideas to produce similar products that are of similar quality." There are more business decisions that occur over a lunch or dinner as opposed to any other time, yet 
no courses teach students how to apply the foundational theoretical knowledge learned in school to the real-world challenges we face.

Undoubtedly, academic institutions and employers are under a vast amount of pressure. Academia must produce a certain number of graduates, practically pumping out graduates on an assembly line, while employers are expected to hire only the best. However, there are significant advantages of upskilling students that will address the inadequacies of our current economic and academic structures.

Mentorship and coaching programs at a younger age are needed to help students understand what options they have in their future endeavors. These programs need to be instated by the provincial and territorial mandate, enforced at a regional level and customized at a micro level, based on the local demographic. Today we have individuals taking English literature ending up in software engineering roles, and we have history majors applying to the hospitality industry. Courses do not teach us experience, but there is capacity to teach transferable skills if our federal mandate includes the provision of mandatory experiential learning.

As previously discussed, a global online platform is another solution to bridging the current disconnect that exists between employers and institutions. This could be supported by the federal government in partnership with major employers. This would allow students the opportunity to take part in experiential learning earlier in their academic trajectory and would allow students to see the vast amount of information they learn in school and make the connections in what they want to achieve. Integrating and synthesizing the information and having the creative freedom to pursue their passion will drive talent to come forward in ways like we've never seen before. Striving towards a model that involves coordination will lead to a shared understanding that defines the top competencies that universities can start building. Once institutions start building common definitional expectations and outcomes-based expectations, a mutually agreed upon environment can be successful. The current lack of a shared language needs to be addressed.

In addition, we need more venture companies coming forward and taking advantage of existing capital that is being saved due to remote work. Every city has some sort of Chamber of Commerce or equivalent that can be part of the model of change. For instance, in launching the online platform, collaborative efforts may choose to do this in the form of an app - a mobile marketing app that would potentially match students and employers, while data sharing pertinent information. This structure of information exchange can help serve as the regions' connector and can help to provide labour market information that is driving the main search for current occupation openings. In conclusion, institutions need to better prepare students for the employability through experiential learning opportunities, and second, employers need to strengthen their partnerships with academic institutions.

\section{References}

Alison. (2021). A Growing Skills Gap is Leading to Greater Inequality. Online Learning can Change This. Retrieved from: https://alison.com/ media-centre/articles/a-growing-skills-gap-is-leading-togreater-inequality-onlinelearning-can-change-this Appleby, D. C. (2017). The soft skills college students need to succeed now and in the future. American Psychological Association. Retrieved from: https://www.apa.org/ed/ precollege/psn/2017/09/softskills

Bain, K. (2021). Super Courses: The Future of Teaching and Learning: The Future of Teaching and Learning. Princeton University Press.

Berlyne, D. E. (1954). An experimental study of human curiosity. British Journal of Psychology, 45: 256-265.

Caldwell, M. (2020). 'Schools are killing curiosity': why we need to stop telling children to shut up and learn. The Guardian. Retrieved from: https:// www.theguardian.com/education/2020/jan/28/schools-killing-curiosity-learn

Deci, E. L., Ryan, R. M., Williams, G. C. (1996). Need Satisfaction and the Self-Regulation of Learning. Learning and Individual Differences, 
8(3): 165-183.

Douglass, J. A. \& Edelstein, R. (2009). THE GLOBAL COMPETITION FOR TALENT: The Rapidly Changing Market for International Students and the Need for a Strategic Approach in the US. Center for Studies in Higher Education, 8.09.

Du Toit-Brits, C. (2018). Towards a transformative and holistic continuing self-directed learning theory. South African Journal of Higher Education, 32(4): 51-65.

Erickson, C. L. \& Norlander, P. (2021). How the Past of Outsourcing and Offshoring is the Future of Post-Pandemic Remote Work: A Typology, a Model, and a Review. SSRN.

Gandolf, S. (2021). Competition is increasing - rapidly and dramatically. Healthcare Success. Retrieved from: https:// healthcaresuccess.com/blog/ healthcare-marketing/competition.html

Garnero, A. \& Pagani, F. (2021). Breakingviews - Guest view: Dislocation will be 2021's buzzword. Reuters. Retrieved from: https://www.reuters. com/article/us-health-coronavirus-economy-breakingvi-idUSKBN29I16Y

Harter, S. (1978). Pleasure Derived from Challenge and the Effects of Receiving Grades on Children's Difficulty Level Choices. Child Development, 49(3): 788-799.

Howard-Jones, P. A. \& Demetriou, S. (2009). Uncertainty and engagement with learning games. Inst Science, 37: 519536.

Hu, Y. \& Ma, J. (2016). Talent Training in Commodities on the basis of "Six-dimensional Synergy" School-enterprise Cooperation. School-Enterprise Cooperation: 377-380.

Jirout, J. J. (2020). Supporting Early Scientific Thinking Through Curiosity. Front Psychol (11): 1717.

Kumar, R. \& Tan, B. S. (2018). Innovative Education: Public-Private Partnership for Developing International Trading Talent. SSRN. http://dx.doi. org/10.2139/ssrn.3149239

Kwarteng, A. B. (2014). Identifying employee talent for development and retention. PhD Diss. Retrieved from: http://ir.knust.edu.gh/handle/123456789/7631

Lambert, P. (2021). We Need More Robust Employer-Education Partnerships. Paul Lambert Consulting. Retrieved from: https://www.paulwlambert. com/blog/we-need-more-robust-employer-education-partnerships

Lazebnikova, A., Koval, T. \& Frantsuzova, O. (2019). Potential of Secondary School Social Sciences in Formation of Students' Universal Skills. The European Proceedings of Social \& Behavioural Sciences: 504-512.

Leonard, P. M. (2020). COVID-19 and the New Technologies of Organizing: Digital Exhaust, Digital Footprints, and Artificial Intelligence in the Wake of Remote Work. Journal of
Management Studies.

Nagele, C. \& Stalder, B. E. (2017). Competence and the Need for Transferable Skills. Competence-based Vocational and Professional Education: 739-753.

Nijhof, W. J. \& Brandsma, J. (1999). Bridging the Skills Gap between Work and Education. Springer Netherlands.

Nordstrom, K. \& Ridderstrale, J. (2001). Funky Business: Talent Makes Capital Dance ( $2^{\text {nd }}$ Edition). Pearson International.

Matern, J-L. (2020). Mass collaboration between employers and universities is the future of higher education. Retrieved from: https://medium.com/ emerge-edtech-insights/ mass-collaboration-between-employers-and-universities-is-the-future-of-higher-education-part-1-ed840467 bfd5 Mishra, P. T. \& Mishra, A. (2019). Role of Higher Education in Bridging the Skill Gap. Universal Journal of Management, 7(4): 134-139.

Muhamad, S. (2012). Graduate Employability and Transferable Skills: A Review. $A d$ vances in Natural and Applied Sciences, 6(6): 882-885.

Murphy, M. C. \& Dweck, C. S. (2009). A Culture of Genius: How an Organization's Lay Theory Shapes People's Cognition, Affect, and Behavior. Personality and Social Psychology Bulletin, 36(3):283296. 
Mulheisen, M. (3018). The Long and Short of the Digital Revolution. Finance \& Development, 55(2).

Pissarides, K. (2020). Outsourcing relevancy in a post COVID-19 environment. Delloite. Retrieved from: https://www2.deloitte.com/cy/ en/pages/tax/articles/outsourcing_relevancy post covid19 environment.html

Reed, D., Haroon, J. \& Ryan, P. S. (2014). Technologies and Policies to Connect the Next Five Billion. Berkeley Technology Law Journal, 29(2): 1205-1252.

Rogerson, C. \& Scott, E. (2010). The Fear Factor: How It Affects Students Learning to Program in a Tertiary Environment. Journal of Information Technology Education, 9. Salzman, A. (2020). Inside Saudi Arabia's \$360 Billion Investment Fund. Retrieved from: https://www.barrons.com/ articles/interview-with-yasiral-rumayyan-head-of-saudiarabias-sovereign-wealthfund-51600453301

Trzesniewski, K. H., Donnellan, M. B., Moffitt, T. E., Robins, R. W., Poulton, R. \& Caspi, A. (2006). Low self-esteem during adolescence predicts poor health, criminal behavior, and limited economic prospects during adulthood. Dev Psychol, 42(2): 381-390.

World Economic Forum. (2016). The Fourth Industrial Revolution: what it means, how to respond. Retrieved from: https://www.weforum.org/ agenda/2016/01/the-fourthindustrial-revolution-what-itmeans-and-how-to-respond/

Young, K. E. (2020). Sovereign risk: Gulf sovereign wealth funds as engines of growth and political resource. British Journal of Middle Eastern Studies, 47(1): 96-116.

Xu, M., David, J. M. \& Kim, S. H. (2018). The Fourth Industrial Revolution: Opportunities and Challenges. International Journal of Financial Research, 9(2). 